\title{
ANALISA METODE SHA384 UNTUK MENDETEKSI ORISINALITAS CITRA DIGITAL
}

\author{
Putri M. Simanullang ${ }^{1}$, Sinar Sinurat ${ }^{2}$, Imam Saputra $^{3}$ \\ Program Studi Teknik Informatika STMIK Budi Darma, Medan, Indonesia \\ Email: ${ }^{1}$ putrimsimanullang05@gmail.com
}

\begin{abstract}
Abstrak
Kriptografi digunakan untuk menjaga keamanan dari suatu isi atau informasi yang bersifat pribadi dari siapapun kecuali yang memiliki otoritas atau kunci rahasia untuk membuka informasi yang telah disandi. Seiring perkembangan teknologi dan komputer sekarang, peningkatan kejahatan komputer pun semakin meningkat terutama dalam manipulasi citra. Banyak cara yang di gunakan dan dilakukan orang untuk memanipulasi citra yang berdampak merugikan orang lain. Orisinalitas citra digital adalah keaslian dari citra tersebut baik dari segi warna, bentuk, objek dan informasi tanpa ada perubahan sedikitpun dari pihak lain. Saat ini banyak citra digital yang beredar di internet yang sudah di manipulasi dan bahkan citra sudah digunakan untuk bahan kecurangan dalam kompetisi, sehingga dibutuhkan suatu metode yang bisa untuk mendeteksi citra tersebut asli atau palsu seperti halnya ijazah. Dalam penelitian ini, penulis menggunakan metode SHA-384 untuk mendeteksi orisinalitas citra digital, dengan menggunakan metode ini citra yang masih diragukan keasliannya dapat di ketahui citra tersebut asli atau palsu.
\end{abstract}

Kata kunci: Orisinalitas, Citra, SHA-384

\begin{abstract}
Cryptography is used to maintain the security of content or information that is personal from anyone except those who have the authority or secret key to open the information that has been encoded. Along with the development of technology and computers now, the increase in computer crime has also increased, especially in image manipulation. Many methods are used and carried out by people to manipulate images that have a detrimental effect on others. The originality of a digital image is the authenticity of the image in terms of colors, shapes, objects and information without the slightest change from the other party. Nowadays many digital images circulating on the internet have been manipulated and even images have been used for material fraud in the competition, so we need a method that can detect the image is authentic or fake like a diploma.In this study, the authors used the SHA-384 method to detect the originality of digital images, using this method an image that is still doubtful of its authenticity can be found out that the image is authentic or fake.
\end{abstract}

Keywords: Originality, Citra, SHA-384

\section{PENDAHULUAN}

Gambar (citra) sering digunakan dalam menyajikan informasi. Gambar pun tidak lepas dari masalah keamanan, salah satu masalah yang umum ditemui pada gambar adalah data tersebut dapat diambil oleh pihak yang tidak berhak dan tidak bertanggung jawab yang kemudian disalahgunakan untuk hal-hal yang tidak diinginkan. Kriptografi berperan penting dalam layanan keamanan seperti kerahasiaan, integritas data, otentikasi dan pencegahan penyangkalan dalam bentuk file maupun citra digital [1]. Kriptografi menggunakan berbagai macam teknik dalam upaya untuk mengamankan data termasuk gambar. Penyandian data gambar melalui media elektronik memerlukan suatu proses yang dapat menjamin keamanan data gambar dan keutuhan dari data gambar tersebut [2]. Data gambar tersebut harus tetap rahasia dengan bertujuan untuk menjaga kerahasiaannya terhadap orang-orang yang tidak berhak.

Misalnya masalah keaslian ijazah sangat penting dilakukan karena banyak pemalsuan ijazah terjadi. Baik itu oleh perusahaan yang akan menerima karyawan, pendaftaran calon pimpinan atau kepala daerah, penerimaan CPNS, maupun oleh para pemilik ijazah itu sendiri. Karena canggihnya teknologi sekarang ini, memalsukan ijazah pun sudah sangat mungkin dilakukan oleh pihak-pihak yang tidak bertanggung jawab. Apalagi ketatnya persaingan kerja, persaingan kursi jabatan dan mahalnya nilai yang harus dikeluarkan untuk mendapatkan sebuah ijazah. Jadi dalam penerapan untuk membuktikan bahwa ijasah tersebut asli atau sudah pernah dimanipulasi dengan memerlukan fungsi hash dan metode SHA384. Fungsi hash yaitu fungsi yang menerima masukan string yang panjangnya sembarang dan mengonversinya menjadi string keluaran yang panjangnya tetap. Fungsi hash menghasilkan keluaran yang dinamakan Message Digest (MD). Federal Information Processing Standards (FIPS) menetapkan standar kriptografi untuk ijazah digital adalah Digital Signature Standard (DSS). Dalam implementasinya, terdapat begitu banyak variasi metode Digital signature, salah satunya adalah DSSR. DSSR dapat diimplementasikan dalam banyak hal, salah satunya adalah untuk legalisasi digital suatu ijazah dan transkrip nilai seseorang. SHA-384 didefinisikan dengan cara yang sama persis seperti SHA-512 dengan dua pengecualian berikut: (1) nilai hash awal $H^{(0)}$ didasarkan pada bagian fraksional dari akar kuadrat dari bilangan prima ke sembilan hingga ke enam belas, (2) hash 384 bit terakhir diperoleh dengan memotong hash berbasis SHA-512 yang diletakkan di sebelah paling kiri 384 bit. Kelebihan dari metode SHA384 yaitu perubahan sekecil apapun pada data asli akan membuat nilai hash yang sangat jauh berbeda, sehingga cukup mudah untuk memeriksa keaslian data, memiliki ukuran message digest 512/384 bit, ukuran blok pesan 1024 bit dan 
tidak kolisi. Kekurangan dari metode ini adalah memiliki kemungkinan untuk terjadi bentrokan, hal ini tidak dapat dihindari untuk semua fungsi hash, namun ada beberapa fungsi hash dibuat khusus untuk menghindari terjadinya bentrokan.

\section{TEORITIS}

\subsection{Kriptografi}

Kriptografi (cryptography) berasal dari bahasa Yunani, yaitu cryptos yang berarti secret (rahasia), sedangkan graphien artinya writing (tulisan). Jadi secara asal bahasa kriptografi berarti secret writing (tulisan rahasia). Kriptografi memiliki beberapa definisi. Salah satu definisi kriptografi adalah ilmu yang mempelajari teknik-teknik matematika yang berhubungan dengan aspek keamanan informasi seperti kerahasiaan, integritas data, serta otentifikasi [3].

\subsection{SHA-384}

SHA-348 (348 bit) adalah bagian dari rangkaian fungsi hash kriptografis SHA-2, yang dirancang oleh Badan Keamanan Nasional AS (NSA) dan diterbitkan pada tahun 2001 oleh NIST sebagai Standar Pemrosesan Informasi Federal AS (FIPS). Fungsi hash adalah algoritma yang mengubah (hashes) set elemen data yang sewenang-wenang, seperti file teks, menjadi nilai panjang tetap tunggal (hash). Nilai hash yang dikomputasi kemudian dapat digunakan untuk memverifikasi integritas salinan data asli tanpa menyediakan sarana apa pun untuk memperoleh data asli tersebut. Tidak dapat diubah lagi, nilai hash dapat didistribusikan secara bebas, disimpan, dan digunakan untuk tujuan perbandingan. SHA adalah singkatan dari Secure Hash Algorithm. SHA-2 mencakup sejumlah besar perubahan dari pendahulunya [4].

Langkah-Langkah Metode SHA-384:

1. Strukur SHA-384

Fungsi hash SHA-384 menghasilkan digest berukuran 384 bit dengan menggunakan iterasi blok pesan berukuran 1024 bit. Struktur SHA-384 dengan niai $m=384$ dan $n=1024$. Pada awalnya pesan ditambah terlebih dahulu dengan padding agar memiliki panjang yang habis dibagi dengan 1024 . Nilai $H_{0}$ (digest awal) ditentukan terlebih dahulu, kemudian secara berulang menghabiskan $H_{i}$ dengan memanggil fungsi kompresi yang memiliki 2 masukan, yaitu $H_{i-1}$ dan $M_{i}$ (blok pesan ke-i) [5].

2. Padding

Sebelum pesan asli $M$ dihitung nilai digest-nya oleh fungsi kompresi, hal pertama yang dilakukan adalah menambah padding dan informasi panjang $M$. Total jumlah bit pesan asli $M$, padding dan informasi panjang $M$ harus merupakan kelipatan 1024 bit. Nilai padding yang digunakan adalah $100 \ldots . .0$ dengan panjang padding yang bervariasi. Sedangkan panjang informasi panjang pesan asli adalah 96 bit. Ukuran padding dapat dihitung dengan [5]:

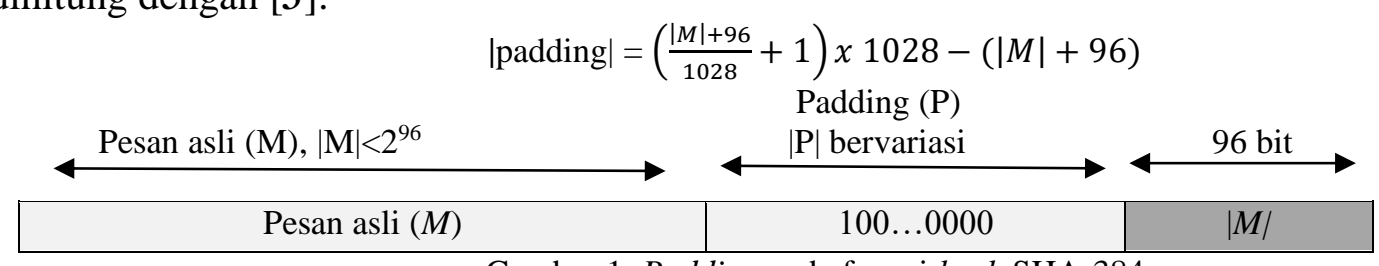

3. Fungsi Kompresi SHA-384

Gambar 1. Padding pada fungsi hash SHA-384

Fungsi kompresi SHA-384 memiliki 2 masukan: digest blok sebelumnya atau digest inisial berukuran 384 bit dan blok pesan terkini dengan ukuran 1024 bit. Pengolahan pada fungsi kompresi berorientasi word berukuran 64 bit. Fungsi kompresi terdiri dari 80 ronde dengan masukan ronde ke-i adalah 8 word konstan $K_{i}$. [5].

4. Digest Inisial

Fungsi hash SHA-384 menggunakan nilai digest awal yang sudah diterapkan. Nilai digest inisial merupakan 8 word yang diambil dari bagian pecahan pada akar kuadrat 8 bilangan prima pertama yaitu $\{2,3,5,7,11$,

$13,17,19\}$ seperti yang ditunjukkan oleh tabel $2.1[5]$.

5. Ekspansi Words

Blok pesan berukuran 1024 bit atau 16 word, tetapi pada fungsi kompresi SHA-384 terdiri dari 80 ronde sehingga dibutuhkan 80 words.

\begin{tabular}{cc} 
Tabel 1. Nilai digest inisial dalam heksadesimal \\
\hline$H_{0}[0]$ & 6A09E667F3BCC908 \\
$H_{0}[1]$ & BB67AE8584CAA73B \\
$H_{0}[2]$ & 3C6EF372FE94F82B \\
$H_{0}[3]$ & A54FF53A5F1D36F1 \\
$H_{0}[4]$ & 510E527FADE682D1 \\
\hline
\end{tabular}




$\begin{array}{cc}H_{0}[5] & \text { 9B05688C2B3E6C1F } \\ H_{0}[6] & \text { 1F83D9ABFB41BD6B } \\ H_{0}[7] & \text { 5BE0CD19137E2179 }\end{array}$

Karena tiap ronde membutuhkan 1 word, maka dibutuhkan algoritma ekspansi words yang membuat 80 word dengan masukan 16 word blok pesan.

Misalnya word hasil keluaran ekspansi words adalah $W_{0}, W_{1}, \ldots, W_{79}$. Maka ekspansi words menetapkan $W_{0}, \ldots$, $W_{15}$ bernilai sama dengan blok pesan sedangkan untuk word selanjutnya dilakukan perhitungan dengan persamaan berikut:

$W_{i}=W_{i-16}+$ RotShift $_{1-8-7}\left(W_{1-15}\right)+W_{1-7}+\operatorname{RotShift}_{19-16-6}\left(W_{i-2}\right)$

Dengan + adalah operator penjumlah modulus $2^{64}$ dan fungsi RotShift 1 -m-n didefinisikan sebagai berikut:

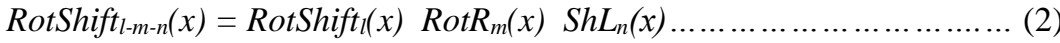

Dengan RotR adalah fungsi bit gesr berputar ke kanan dan ShL adalah fungsi bit geser ke kiri [5].

6. Struktur Tiap Ronde

Setiap ronde pada fungsi kompresi SHA-384 mengubah nilai digest dengan cara menggeser ke kanan digest dalam satu word,namun untuk word ke-0 dan 4 diisi dari perhitungan khusu seperti yang ditunjukkan oleh Gambar 2.5. Ronde SHA-384 menggunakan 4 fungsi khusu yang beroperasi pada level bit, yaitu majority, rotate,conditional dan + yang didefinisikan berikut:

Ronde $\mathrm{i}$

\begin{tabular}{|c|c|c|c|c|c|c|c|}
\hline $\mathbf{A}$ & B & C & D & $\mathbf{E}$ & $\mathbf{F}$ & G & H \\
\hline $\mathbf{X}$ & $\mathbf{A}$ & B & $\mathbf{C}$ & $\mathbf{Y}$ & $\mathbf{E}$ & $\mathbf{F}$ & $\mathbf{G}$ \\
\hline
\end{tabular}

$\mathrm{T}=\mathrm{w}+\mathrm{K}+\mathrm{H}+$ conditional $(\mathrm{E}, \mathrm{F}, \mathrm{G})+$ rotate $(\mathrm{E})$

$\mathrm{X}=$ majority $(\mathrm{A}, \mathrm{B}, \mathrm{C})+\operatorname{rotate}(\mathrm{A})+\mathrm{T}$

$\mathrm{Y}=\mathrm{T}+\mathrm{D}$

7. Fungsi hash SHA384

Gambar 2. Struktur ronde pada fungsi kompresi SHA-384

Fungsi hash SHA-384 memiliki masukan pesan dengan ukuran lebih kecil dari pada $2^{96}$ dan keluaran sebuah digest berukuran 384 bit. Fungsi hash menggunakan fungsi kompresi secara berulang dengan membagi pesan menjadi $N$ blok berukuran 1024 bit. Fungsi hash menerima masukan sebuah pesan, indeks awal pesan dan panjang pesan dan mengembalikan message digest pesan. Berikut ini beberapa nilai message digest yang dikembalikan oleh fungsi hash [5]:

Hash (" ") =

CF83E1357EEFB8BDF1542850D66D8007D620E4050B5

715DC83F4A921D36CE47D0D13C5D85F2B0FF8318

D2877EEC2F63B931BD47417A81A538327AF927DA3E

Hahs ("abc") =

DDAF35A193617ABACC417349AE20413112E6FA4E89A

97EA20A9EEEE64B55D39A2192992A274FC1A836BA3C

23A3FEEBBD454D4423643CE80E2A9AC94FA54CA49F

Hahs ("The quick brown fox jumps over the lazy dog") =

07E547D9586F6A73F73FBAC0435ED76951218FB7D0C

8D788A309D785436BBB642E93A252A954F23912547D

1E8A3B5ED6E1BFD7097821233FA0538F3DB854FEE6

8. Keamanan SHA384

Fungsi hash SHA-384 dapat dinilai tingkat keamanan nya dengan mengevaluasi ketahanan terhadap 3 serangan fungsi hash, yaitu: serangan preimage, serangan second preimage dan serangan collision. Menurut pengembangnya SHA-384 tahan terhadap ketiga serangan tersebut karena memiliki ukuran digest yang besar, yaitu 384 bit sehingga mempersiapkan serangan preimage, second preimage dan collision membutuhkan sangat banyak pesan yang membuat serangan menjadi tidak layak [5].

Kontanta yang sudah menjadi ketetapan yaitu:

428a2f98d728ae22 7137449123ef65cd

$3956 \mathrm{c} 25 \mathrm{bf} 348 \mathrm{~b} 538 \quad$ 59f111f1b605d019

d807aa98a3030242 12835b0145706fbe

$72 \mathrm{be} 5 \mathrm{~d} 74 \mathrm{f} 27 \mathrm{~b} 896 \mathrm{f}$

e49b69c19ef14ad2

2de92c6f592b0275

$983 \mathrm{e} 5152 \mathrm{ee} 66 \mathrm{dfab}$

c6e00bf33da88fc2 b5c0fbcfec $4 \mathrm{~d} 3 \mathrm{~b} 2 \mathrm{f}$

$923 \mathrm{f} 82 \mathrm{a} 4 \mathrm{af} 194 \mathrm{f} 9 \mathrm{~b}$

243185be4ee4b28c

9bdc06a725c71235

0fc19dc68b8cd5b5

$5 \mathrm{cb} 0 \mathrm{a} 9 \mathrm{dcbd} 41 \mathrm{fbd} 4$

b00327c898fb213f

06ca6351e003826f e9b5dba58189dbbc

ab1c5ed5da6d8118

$550 \mathrm{c} 7 \mathrm{dc} 3 \mathrm{~d} 5 \mathrm{ffb} 4 \mathrm{e} 2$

c19bf174cf692694

240ca1cc77ac9c65

76f988da831153b5

bf597fc7beef0ee 4

142929670a0e6e70 


$\begin{array}{ll}\text { 27b70a8546d22ffc } & \text { 2e1b21385c26c926 } \\ \text { 650a73548baf63de } & \text { 766a0abb3c77b2a8 } \\ \text { a2bfe8a14cf10364 } & \text { a81a664bbc423001 } \\ \text { d192e819d6ef5218 } & \text { d69906245565a910 } \\ \text { 19a4c116b8d2d0c8 } & \text { 1e376c085141ab53 } \\ \text { 391c0cb3c5c95a63 } & \text { 4ed8aa4ae3418acb } \\ \text { 748f82ee5defb2fc } & \text { 78a5636f43172f60 } \\ \text { 90befffa23631e28 } & \text { a4506cebde82bde9 } \\ \text { ca273eceea26619c } & \text { d186b8c721c0c207 } \\ \text { 06f067aa72176fba } & \text { 0a637dc5a2c898a6 } \\ \text { 28db77f523047d84 } & \text { 32caab7b40c72493 } \\ \text { 4cc5d4becb3e42b6 } & \text { 597f299cfc657e2a }\end{array}$

$27 \mathrm{~b} 70 \mathrm{a} 8546 \mathrm{~d} 22 \mathrm{ffc}$

\author{
$2 \mathrm{e} 1 \mathrm{~b} 21385 \mathrm{c} 26 \mathrm{c} 926$ \\ d69906245565a910 \\ $1 \mathrm{e} 376 \mathrm{c} 085141 \mathrm{ab} 53$ \\ 4ed8aa4ae3418acb \\ a4506cebde82bde9 \\ d186b8c721c0c207 \\ $597 \mathrm{f} 299 \mathrm{cfc} 657 \mathrm{e} 2 \mathrm{a}$
}

4d2c6dfc5ac42aed
$81 \mathrm{c} 2 \mathrm{c} 92 \mathrm{e} 47$ edaee6
c24b8b70d0f89791
f40e35855771202a
2748774cdf8eeb99
5b9cca4f7763e373
84c87814a1f0ab72
bef9a3f7b2c67915
eada7dd6cde0eb1e
113f9804bef90dae
3c9ebe0a15c9bebc
5fcb6fab3ad6faec

$53380 \mathrm{~d} 139 \mathrm{~d} 95 \mathrm{~b} 3 \mathrm{df}$ $92722 \mathrm{c} 851482353 \mathrm{~b}$ c76c51a30654be30 106aa07032bbd1b8 $34 \mathrm{~b} 0 \mathrm{bcb} 5 \mathrm{e} 19 \mathrm{~b} 48 \mathrm{a} 8$ 682e6ff3d6b2b8a3 8 cc702081a6439ec c67178f2e $372532 b$ f57d4f7fee6ed 178 $1 \mathrm{~b} 710 \mathrm{~b} 35131 \mathrm{c} 471 \mathrm{~b}$ $431 \mathrm{~d} 67 \mathrm{c} 49 \mathrm{c} 100 \mathrm{~d} 4 \mathrm{c}$ $6 \mathrm{c} 44198 \mathrm{c} 4 \mathrm{a} 475817$

\section{ANALISA DAN PEMBAHASAN}

Analasi adalah penguraian dari suatu pembahasan, dalam hal ini pembahasan mengenai metode SHA-384 untuk mendeteksi orisinalitas citra digital pada hasil scan ijazah. Dalam hal ini yang dideteksi atau diamankan adalah sebuah citra yang dapat mewakili banyak informasi yang bersifat rahasia atau penting. Lemahnya pengetahuan tentang keamanan data gambar memudahkan para manipulaive merekayasa citra seperti manipulation, editing, duplicating, sehingga perlu dilakukan pendeteksian untuk mengetahui keaslian dari citra tersebut. Salah satu solusi yang dapat digunakan untuk menangani permasalahan tersebut adalah dengan teknik kriptografi yaitu menggunakan metode SHA-384.

\subsection{Penerapan Metode SHA-384}

Dalam penyelesaian metode SHA-384 untuk mendeteksi orisinalitas citra digital yaitu hasil scan ijazah diperlukan input atau yang pertama ditentukan adalah ukuran citra yang dideteksi yaitu 5 x 5 . Jadi dalam penerapan untuk membuktikan bahwa ijasah tersebut asli atau sudah pernah dimanipulasi dengan memerlukan fungsi hash dan metode SHA384. Fungsi hash yaitu fungsi yang menerima masukan string yang panjangnya sembarang dan mengonversinya menjadi string keluaran yang panjangnya tetap. Seperti gambar di bawah ini:

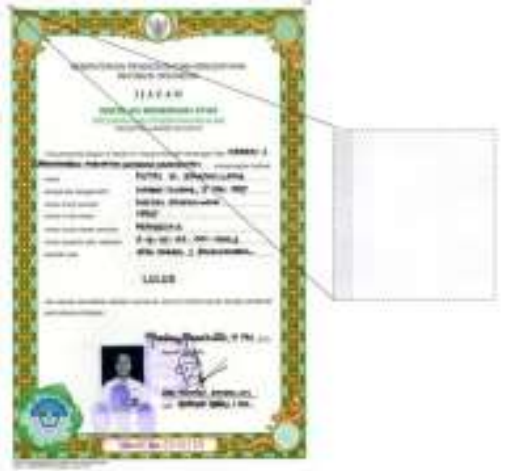

Gambar 3. Input hasil scan ijazah dan area yang dideteksi

Untuk SHA-384, setiap blok pesan memiliki 1024 bit, yang direpresentasikan sebagai urutan enam belas 64-bit kata. SHA-384 menggunakan enam fungsi logis, dimana setiap fungsi beroperasi pada kata-kata 64-bit, yang dirrepresentasikan sebagai $x, y$, dan z. Hasil dari setiap fungsi adalah 64-bit kata yang baru. Berikut nilai desimal dari gambar yang dideteksi dengan ukuran 5 x 5 :

$\begin{array}{lllll}247 & 248 & 250 & 250 & 251 \\ 250 & 250 & 251 & 251 & 251 \\ 251 & 252 & 252 & 252 & 253 \\ 253 & 253 & 252 & 252 & 252 \\ 253 & 253 & 252 & 252 & 253\end{array}$

Tabel 2. Input Hexadesimal

\begin{tabular}{ccccc}
\hline F7 & F8 & FA & FA & FB \\
FA & FA & FB & FB & FB \\
FB & FC & FC & FC & FD \\
\hline
\end{tabular}




$\begin{array}{lllll}\text { FD } & \text { FD } & \text { FC } & \text { FC } & \text { FC } \\ \text { FD } & \text { FD } & \text { FC } & \text { FC } & \text { FD }\end{array}$

Setelah nilai hexsadesimalnya diketahui, maka nilai tersebut konversikan ke bilangan biner. Seperti tabel dibawah ini:

Tabel 3. Biner dari area yang dideteksi

\begin{tabular}{lllll}
\hline 11110111 & 11111000 & 11111010 & 11111010 & 11111011 \\
11111010 & 11111010 & 11111011 & 11111011 & 11111011 \\
11111011 & 11111100 & 11111100 & 11111100 & 11111101 \\
11111101 & 11111101 & 11111100 & 11111100 & 11111100 \\
11111101 & 11111101 & 11111100 & 11111100 & 11111101
\end{tabular}

Berikut langkah- langkah perhitungan nilai pixel dari citra digital mengunakan metode SHA-384 yang terdiri dari 0 79 putaran.

1. Penambahan padding bit:

$l+1+k=896 \bmod 1024$

$l \longrightarrow 5 \times 5=25$

$25 \times 8=200$

Jadi, $l+1+k=896 \bmod 1024 \longrightarrow 200+1+k=896 \bmod 1024$

$k=896-201 \bmod 1024$

$k=695 \bmod 1024$

$k=695$

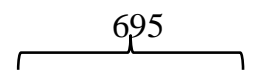

$\mathrm{M}=111101111111100011111010111110101000000 \ldots 0000$

$\mathrm{M}=111101111111100011111010111110101000000 \ldots .0000 \ldots . .11001000$

Lakukan penambahan bit sebanyak 695 dan penambahan panjang pesan sebanyak 64 bit

Tabel 4. Penambahan Bit dan Penambahan Pesan

\begin{tabular}{lllll}
\hline $\mathbf{M}^{(0)}$ & 11110111 & 11111000 & 11111010 & 11111010 \\
$\mathbf{M}^{(1)}$ & 11111011 & 11111010 & 11111010 & 1111011 \\
& 11111011 & 11111011 & 11111011 & 11111100 \\
$\mathbf{M}^{(2)}$ & 11111100 & 11111100 & 11111101 & 11111101 \\
& 11111101 & 11111100 & 11111100 & 11111100 \\
$\mathbf{M}^{(3)}$ & 11111101 & 11111101 & 11111100 & 11111100 \\
& 11111101 & 10000000 & 00000000 & 00000000 \\
$\mathbf{M}^{(4)}$ & 00000000 & 00000000 & 00000000 & 00000000 \\
& 00000000 & 00000000 & 00000000 & 00000000 \\
$\mathbf{M}^{(5)}$ & 00000000 & 00000000 & 00000000 & 00000000 \\
& 00000000 & 00000000 & 00000000 & 00000000 \\
$\mathbf{M}^{(6)}$ & 00000000 & 00000000 & 00000000 & 00000000 \\
& 00000000 & 00000000 & 00000000 & 00000000 \\
$\mathbf{M}^{(7)}$ & 00000000 & 00000000 & 00000000 & 00000000 \\
& 00000000 & 00000000 & 00000000 & 00000000 \\
$\mathbf{M}^{(8)}$ & 00000000 & 00000000 & 00000000 & 00000000 \\
& 00000000 & 00000000 & 00000000 & 00000000 \\
$\mathbf{M}^{(9)}$ & 00000000 & 00000000 & 00000000 & 00000000 \\
& 00000000 & 00000000 & 00000000 & 00000000 \\
$\mathbf{M}^{(10)}$ & 00000000 & 00000000 & 00000000 & 00000000 \\
$\mathbf{M}^{(11)}$ & 00000000 & 00000000 & 00000000 & 00000000 \\
$\mathbf{M}^{(12)}$ & 00000000 & 00000000 & 00000000 & 00000000 \\
& 00000000 & 00000000 & 00000000 & 00000000 \\
& 00000000 & 00000000 & 00000000 & 00000000 \\
& 00000000 & 00000000 & 00000000 \\
& & & &
\end{tabular}


2. Penjadwalan pesan

\begin{tabular}{lllll}
\hline & 00000000 & 00000000 & 00000000 & 00000000 \\
$\mathbf{M}^{(13)}$ & 00000000 & 00000000 & 00000000 & 00000000 \\
& 00000000 & 00000000 & 00000000 & 00000000 \\
$\mathbf{M}^{(14)}$ & 00000000 & 00000000 & 00000000 & 00000000 \\
& 00000000 & 00000000 & 00000000 & 00000000 \\
$\mathbf{M}^{(15)}$ & 00000000 & 00000000 & 00000000 & 00000000 \\
& 00000000 & 00000000 & 00000000 & 11001000 \\
\hline
\end{tabular}

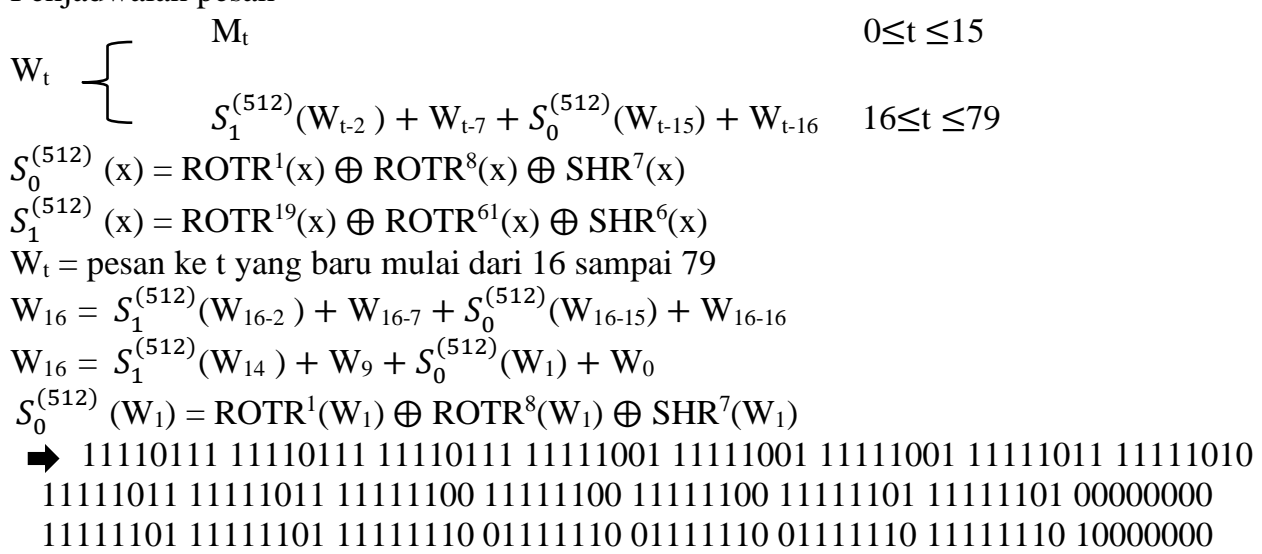

1111110111111101111111100111111001111110011111101111111010000000

$S_{1}^{(512)}\left(\mathrm{W}_{14}\right)=\operatorname{ROTR}^{19}\left(\mathrm{~W}_{14}\right) \oplus \operatorname{ROTR}^{61}\left(\mathrm{~W}_{14}\right) \oplus \mathrm{SHR}^{6}\left(\mathrm{~W}_{14}\right)$

$\Rightarrow 0000000000000000000000000000000000000000000000000000000000000000$ 0000000000000000000000000000000000000000000000000000000000000000 0000000000000000000000000000000000000000000000000000000000000000

0000000000000000000000000000000000000000000000000000000000000000

$\mathrm{W}_{16}=0000000000000000000000000000000000000000000000000000000000000000$

0000000000000000000000000000000000000000000000000000000000000000

1111110111111101111111100111111001111110011111101111111010000000 1111011111111000111110101111101011111011111110101111101011111011

1111010111110110111110010111100101111010011110011111100101111011

Diatas adalah langkah penjadwalan pesan, untuk hasil keseluruhan dari penjadwalan pesan tersebut dibuat ke dalam tabel denganmelakukan langkah yang sama untuk mencari pesan berikutnya, hasilnya adalah seperti tabel di bawah berikut:

Tabel 5. Hasil Nilai Penjadwalan Pesan dari Biner ke Hexadesimal

\begin{tabular}{llll}
\hline W0=f7f8fafafbfafafb & W21=bb4cb53eeb7ea000 & W42=e1f8f118d61d780 & W63=f5f6f9797a02f97b \\
W1=fbfbfbfffcfcfdfd & W22=c1be0a3a45bbc0c8 & W43=efad621e771fc8a0 & W64=f5f6f9797a79f97b \\
W2=fdfcfcfcfdfdfcfc & W23=70d10dc95a21f97b & W44=1f8f118d61d780c8 & W65=1536f9797a79f97b \\
W3=fd80000000000000 & W24=33c81ac764e6ddf5 & W45=d8054b1e14ad2202 & W66=12ef35dc271f4c48 \\
W4=0000000000000000 & W25=c97c2de7974aba7c & W46=40d8054b1e14ad00 & W67=12ef35dc271f4780 \\
W5=0000000000000000 & W26=c81fd33a28227a80 & W47=866d46dd1b754e00 & W68=12ef35dc271f52c8 \\
W6=0000000000000000 & W27=b908026636458e00 & W48=6d46dd1b754e0000 & W69=10edb5dc271f40c8 \\
W7=0000000000000000 & W28=597244d8c81d4000 & W49=ad621e771fc8a000 & W70=12eff5fc271f40c8 \\
W8=0000000000000000 & W29=12ef35dc271f40c8 & W50=cfab5138a9785175 & W71=96af35dc271f46c8 \\
W9=0000000000000000 & W30=eb2884a16172a70b & W51=12ef35dc271f40d0 & W72=f2ef35dc271f47c8 \\
W10=0000000000000000 & W31=2f5ca1f0d86d4534 & W52=52ef35dc271f4040 & W73=32ef35dc271f0000 \\
W11=0000000000000000 & W32=74bf6e1c4c49cf21 & W53=33c81ac764e6dd80 & W74=cf8b513829785100 \\
W12=0000000000000000 & W33=cf8b513829785175 & W54=33c81ac764e6ddc8 & W75=cf8b513829780000 \\
W13=0000000000000000 & W34=866d46dd1b754ec0 & W55=a333c81ac764e6dd & W76=5b3f59784e7ae483 \\
W14=0000000000000000 & W35=11eb172ed451f880 & W56=74bf6e1c4c49cfa & W77=5b3f59784e7ae48c \\
W15=00000000000000c8 & W36=65efad621e771fc8 & W57=54bb6e5c4c49cf21 & W78=5b3f59784e7ae480 \\
W16=f5f6f9797a79f97b & W37=318622954aa6d1b & W58=74bf6e1c4c49cf00 & W79=1f8f118d61d780c8
\end{tabular}



$\mathrm{W} 17=\mathrm{f} 5777777 \mathrm{fc} 36 \mathrm{abf5}$
$\mathrm{W} 38=5 \mathrm{a} 3 \mathrm{f} 8 \mathrm{dd} 006 \mathrm{f} 72 \mathrm{c} 72$
$\mathrm{W} 59=74 \mathrm{bf} 6 \mathrm{e} 1 \mathrm{c} 4 \mathrm{c} 49 \mathrm{c} 021$
$\mathrm{W} 18=8 \mathrm{f} 728 \mathrm{a} 8 \mathrm{e} 53 \mathrm{a} 45 \mathrm{bbc}$
W39=463afebfd $12 \mathrm{dc} 3 \mathrm{c} 6$
$\mathrm{W} 60=74 \mathrm{a} 16 \mathrm{e} 1 \mathrm{c} 4 \mathrm{c} 49 \mathrm{cf} 21$
$\mathrm{W} 19=43 \mathrm{e} 23 \mathrm{c} 4 \mathrm{a} 5202 \mathrm{fd} 40$
$\mathrm{W} 40=40 \mathrm{~d} 8054 \mathrm{~b} 1 \mathrm{e} 14 \mathrm{ad} 22$
$\mathrm{W} 61=\mathrm{f} 5 \mathrm{f} 6 \mathrm{f} 9797 \mathrm{a} 790000$
W20=b333c81 ac764e6dd
$\mathrm{W} 41=162974$ cce $6 \mathrm{f} 10202$
$\mathrm{W} 62=15 \mathrm{~d} 6 \mathrm{f} 9797 \mathrm{a} 79 \mathrm{f} 97 \mathrm{~b}$

3. Initial hash value

Menginisialisasi 8 variabel kerja a, b, c, d, e, f, g dan h

Tabel 6: Menginisialisasi

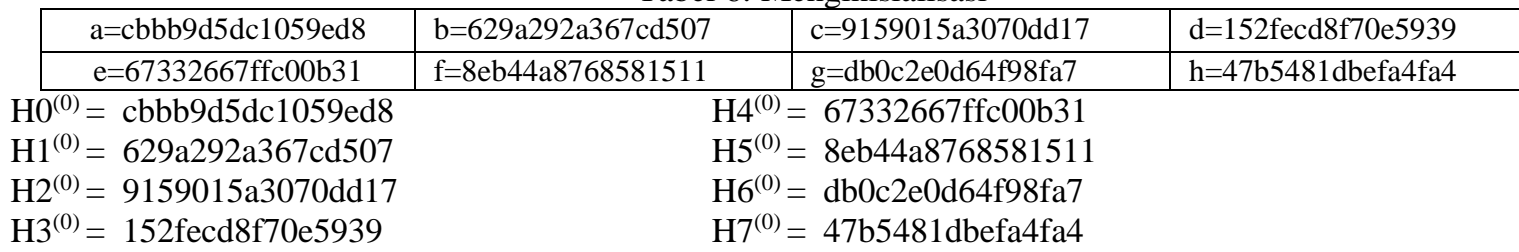

Berikut ini cara pencarian nilai initial hash selanjunya:

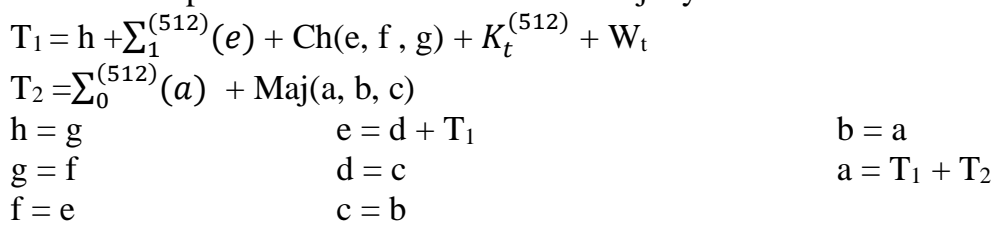

keterangan:

$\mathrm{Ch}(\mathrm{x}, \mathrm{y}, \mathrm{z})=(\mathrm{x} \wedge \mathrm{y}) \oplus(\mathrm{x} \wedge \mathrm{z})$

$\operatorname{Maj}(\mathrm{x}, \mathrm{y}, \mathrm{z})=(\mathrm{x} \wedge \mathrm{y}) \oplus(\mathrm{x} \wedge \mathrm{z}) \oplus(\mathrm{y} \wedge \mathrm{z})$

$\Sigma_{0}^{(512)}(x)=\operatorname{ROTR}^{28}(\mathrm{x}) \oplus \operatorname{ROTR}^{34}(\mathrm{x}) \oplus \operatorname{ROTR}^{39}(\mathrm{x})$

$\sum_{1}^{(512)}(x)=\operatorname{ROTR}^{14}(\mathrm{x}) \oplus \operatorname{ROTR}^{18}(\mathrm{x}) \oplus \operatorname{ROTR}^{41}(\mathrm{x})$

Penyelesain:

Yang pertama kita mencari nilai dari $\mathrm{T}_{1}$ dan $\mathrm{T}_{2}$, dalam pencarian nilai $\mathrm{T}_{1}$ dan $\mathrm{T}_{2}$ kita harus mencari nilai dari $\sum_{1}^{(512)}(e)$, nilai $\mathrm{Ch}(\mathrm{e}, \mathrm{f}, \mathrm{g}), \sum_{0}^{(512)}(a)$, Maj(a, b, c) dan nilai $K_{t}^{(512)}$ seperti langkah dibawah ini. Namun nilai $\mathrm{K}$ (konstanta) tersebut sudah ketentuan seperti yang ada di bab 2.

$\mathrm{T}_{1}=\mathrm{h}+\sum_{1}^{(512)}(e)+\mathrm{Ch}(\mathrm{e}, \mathrm{f}, \mathrm{g})+K_{t}^{(512)}+\mathrm{W}_{\mathrm{t}}$

$\mathrm{T}_{1}=47 \mathrm{~b} 5481 \mathrm{dbefa} 4 \mathrm{fa} 4+\sum_{1}^{(512)}(e)+\mathrm{Ch}(\mathrm{e}, \mathrm{f}, \mathrm{g})+K_{t}^{(512)}+\mathrm{f} 7 \mathrm{f} 8 \mathrm{fafafbfafafb}$

$\sum_{1}^{(512)}(e)=\operatorname{ROTR}^{14}(\mathrm{e}) \oplus \operatorname{ROTR}^{18}(\mathrm{e}) \oplus \operatorname{ROTR}^{41}(\mathrm{e})$

1100100110011001111111111111000000000010110011000100000000000000

1001100110011111111111110000000000101100110001000000000000000000 1000000000010110011000100000000000000000000000000000000000000000

1101000000010000011000101111000000101110000010000100000000000000 d01062f02e084000

$\mathrm{Ch}(\mathrm{e}, \mathrm{f}, \mathrm{g})=(\mathrm{e} \wedge \mathrm{f}) \oplus(\mathrm{e} \wedge \mathrm{g})$

$67332667 \mathrm{ffc} 00 \mathrm{~b} 31 \wedge 8 \mathrm{eb} 44 \mathrm{a} 8768581511=630020768400111$

$67332667 \mathrm{ffc} 00 \mathrm{~b} 31 \wedge \mathrm{db} 0 \mathrm{c} 2 \mathrm{e} 0 \mathrm{~d} 64 \mathrm{f} 98 \mathrm{fa} 7=4300260564 \mathrm{c} 00 \mathrm{~b} 21$

$630020768400111 \oplus 4300260564 \mathrm{c} 00 \mathrm{~b} 21=453024020 \mathrm{c} 800 \mathrm{a} 30$

$\mathrm{T}_{1}=47 \mathrm{~b} 5481 \mathrm{dbefa} 4 \mathrm{fa} 4+\mathrm{d} 01062 \mathrm{f} 02 \mathrm{e} 084000+453024020 \mathrm{c} 800 \mathrm{a} 30+428 \mathrm{a} 2 \mathrm{f} 98 \mathrm{~d} 728 \mathrm{ae} 22+\mathrm{f} 7 \mathrm{f} 8 \mathrm{fafafbfafafb}$

$=9778 \mathrm{f} 9 \mathrm{a} 3 \mathrm{cca} 642 \mathrm{f} 1$

$\mathrm{T}_{2}=\sum_{0}^{(512)}(a)+\operatorname{Maj}(\mathrm{a}, \mathrm{b}, \mathrm{c})$

$\sum_{0}^{(512)}(a)=\operatorname{ROTR}^{28}(\mathrm{a}) \oplus \operatorname{ROTR}^{34}(\mathrm{a}) \oplus \operatorname{ROTR}^{39}(\mathrm{a})$

1101110000010000010110011110110110000000000000000000000000000000 0000010000010110011110110110000000000000000000000000000000000000 1000001011001111011011000000000000000000000000000000000000000000

0101101011001001010011101000110110000000000000000000000000000000

$5 \mathrm{ac} 94 \mathrm{e} 8 \mathrm{~d} 80000000$

$\operatorname{Maj}(a, b, c)=(a \wedge b) \oplus(a \wedge c) \oplus(b \wedge c)$

cbbb9d5dc1059ed $\wedge \wedge 629 \mathrm{a} 292 \mathrm{a} 367 \mathrm{~cd} 507=429 \mathrm{a} 090800049400$

cbbb9d5dc1059ed $8 \wedge 9159015 \mathrm{a} 3070 \mathrm{dd} 17=8119015800009 \mathrm{c} 10$ 
$\mathrm{T}_{2}=5 \mathrm{ac} 94 \mathrm{e} 8 \mathrm{~d} 80000000+\mathrm{c} 39 \mathrm{~b} 095 \mathrm{a} 3074 \mathrm{dd} 17$

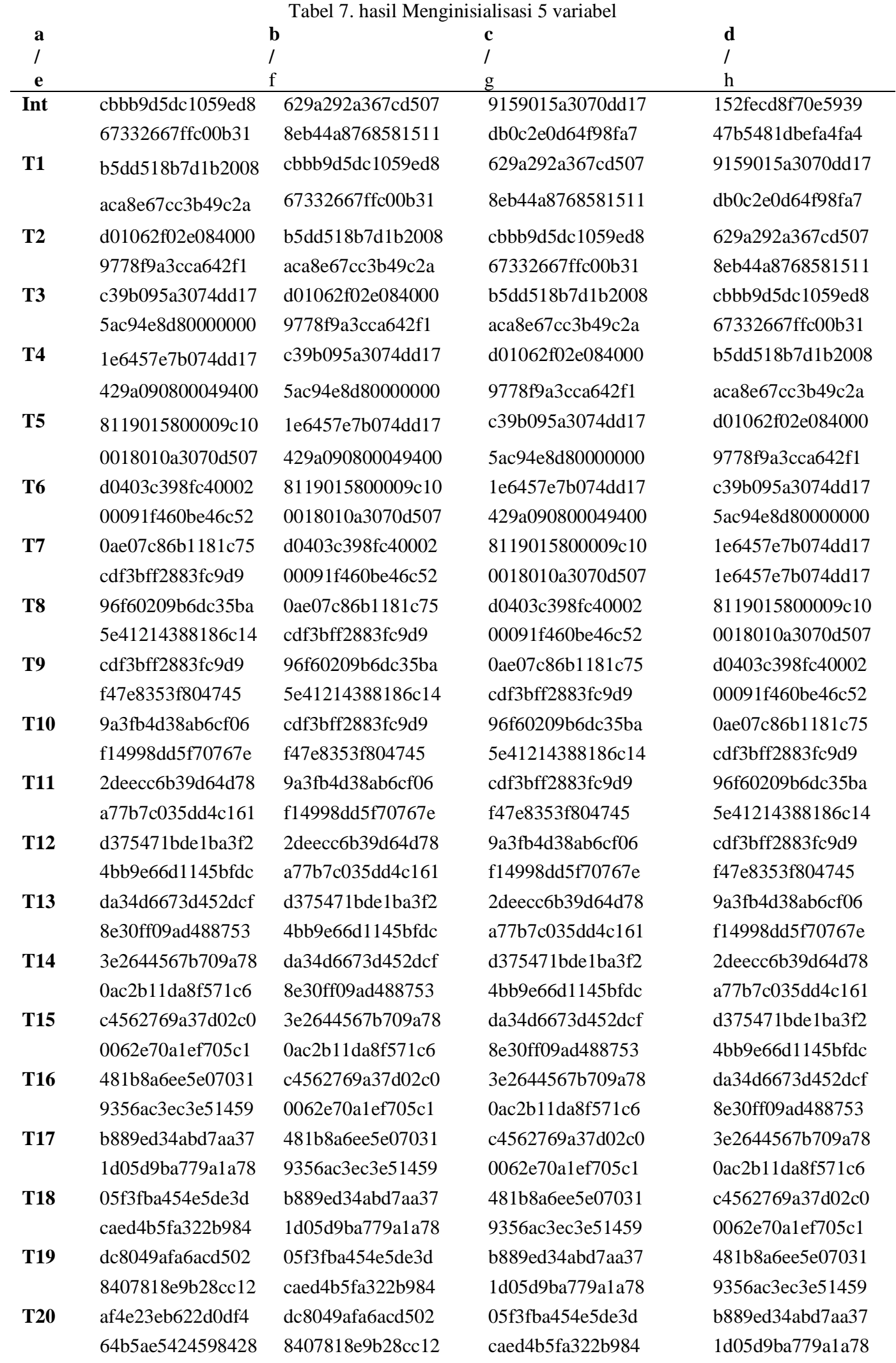


T21

7196e8fa538ba4bf 046735513 cdd $14 d 3$

T22 1f0720944dbeb6a4 a41eb7e5a27588e3 d6d4f8608b8ab199 24b9c216f915da60 88761eb67845978e 9fe22e39448d50ed

T25 7d40e6be47d85702 d9c900e01968c33e

T26 7d0d988df5768598 $2 \mathrm{ec} 2 \mathrm{e} 522 \mathrm{a} 7 \mathrm{c} 7 \mathrm{~d} 12 \mathrm{c}$

T27 6bc425af294bbf79 6a8143b1716ee33d

be0b7e70bdabe53 bb3fcd7585b59e32 2201c7cbd34e 31 fe $0 \mathrm{e} 109 \mathrm{efc} 47927341$ d43e5686506fa05d $807 f 45784852303 \mathrm{f}$ 082ee70d3f352aac

T40 d9c523173b1a1e05 e301dca32c44ca05

T41 b6df019ca515cafb 754b3a461a665640

T42 a7dcaffdbefb9d4a 9e46e9f915099c34

T43 d9c523173b1a1e05 e301dca32c44ca05

T44 b4838c1c28fee7bc f5794711 faa60f63 371f12f333f7e5b9

\section{af4e23eb622d0df4} 64b5ae5424598428 $7196 \mathrm{e} 8 \mathrm{fa} 538 \mathrm{ba} 4 \mathrm{bf}$ 046735513cdd14d3 1 f0720944dbeb6a4 a41eb7e5a27588e3 d6d4f8608b8ab199 24b9c216f915da60 88761eb67845978e 9fe22e39448d50ed 7d40e6be47d85702 d9c900e01968c33e 7d0d988df5768598 $2 \mathrm{ec} 2 \mathrm{e} 522 \mathrm{a} 7 \mathrm{c} 7 \mathrm{~d} 12 \mathrm{c}$ 6bc425af294bbf79 6a8143b1716ee33d af36382c8fd716be a8f8b0033187a916 810ebee951c64ca1 16a64f5997b9cca6 c1af358833cb03c0 d4883c0c21dda190 d5471e3dc7171224 0aaf99c59e7fadbd fb90a8a76dea1bfe 65234d5b5049e665 f517b690d940a294 e4dd663f44d313bc b70883992932880d dc5dd7c12b1cb6e3 8575839b0f08472b bd7176bd099bb2f2 eec6fca5aa657661 7be0b7e70bdabe53 bb3fcd7585b59e32 2201c7cbd34e31fe 0e109efc47927341 d43e5686506fa05d 807f45784852303f 082ee70d3f352aac d9c523173b1a1e05 e301dca32c44ca05 b6df019ca515cafb 754b3a461a665640 a7dcaffdbefb9d4a 9e46e9f915099c34 d9c523173b1a1e05 e301dca32c44ca05 b4838c1c28fee7bc f5794711faa60f63 1e99cae9d4cf0409 ae70c7d11 ea84a83 dc8049afa6acd502 $8407818 \mathrm{e} 9 \mathrm{~b} 28 \mathrm{cc} 12$ af4e23eb622d0df4 64b5ae5424598428 7196e8fa538ba4bf 046735513cdd14d3 1f0720944dbeb6a4 a41eb7e5a27588e3 d6d4f8608b8ab199 24b9c216f915da60 88761eb67845978e 9fe22e39448d50ed 7d40e6be47d85702 d9c900e01968c33e 7d0d988df5768598 2 ec2e $522 \mathrm{a} 7 \mathrm{c} 7 \mathrm{~d} 12 \mathrm{c}$ 6bc425af294bbf79 6a8143b1716ee33d af36382c8fd716be a8f8b0033187a916 810ebee951c64ca1 16a64f5997b9cca6 c1 af358833cb03c0 d4883c0c21dda190 d5471e3dc7171224 0aaf99c59e7fadbd fb90a8a76dea1bfe 65234d5b5049e665 f517b690d940a294 e4dd663f44d313bc b70883992932880d dc5dd7c12b1cb6e3 8575839b0f08472b bd7176bd099bb2f2 eec6fca5aa657661 7be0b7e70bdabe53 bb3fcd7585b59e32 2201c7cbd34e $31 \mathrm{fe}$ 0e109efc47927341 d43e5686506fa05d $807 \mathrm{f} 45784852303 \mathrm{f}$ 082ee70d3f352aac d9c523173b1a1e05 e301dca32c44ca05 b6df019ca515cafb 754b3a461a665640 a7dcaffdbefb9d4a 9e46e9f915099c34 d9c523173b1a1e05 e301dca32c44ca05 b4838c1c28fee7bc f5794711 faa60f63

\begin{abstract}
05f3fba454e 5 de $3 d$ caed4b5fa322b984 dc8049afa6acd502 8407818e9b28cc12 af4e23eb622d0df4 64b5ae5424598428 7196e8fa538ba4bf 046735513cdd14d3 1f0720944dbeb6a4 a41eb7e5a27588e3 d6d4f8608b8ab199 24b9c216f915da60 88761eb67845978e 9fe22e39448d50ed 7d40e6be47d85702 d9c900e01968c33e 7d0d988df5768598 $2 \mathrm{ec} 2 \mathrm{e} 522 \mathrm{a} 7 \mathrm{c} 7 \mathrm{~d} 12 \mathrm{c}$ 6bc425af294bbf79 6a8143b1716ee33d af36382c8fd716be a8f8b0033187a916 810ebee951c64ca1 16a64f5997b9cca6 c1 af $358833 \mathrm{cb} 03 \mathrm{c} 0$ d4883c0c21dda190 d5471e3dc7171224 0aaf99c59e7fadbd fb90a8a76dea1bfe 65234d5b5049e665 f517b690d940a294 e4dd663f44d313bc b70883992932880d dc5dd7c12b1cb6e3 8575839b0f08472b bd7176bd099bb2f2 eec6fca5aa657661 7be0b7e70bdabe53 bb3fcd7585b59e32 2201c7cbd34e31fe 0e109efc47927341 d43e5686506fa05d 807f45784852303f 082ee70d3f352aac d9c523173b1a1e05 e301dca32c44ca05 b6df019ca515cafb

754b3a461a665640 a7dcaffdbefb9d4a 9e46e9f915099c34 d9c523173b1a1e05 e301dca32c44ca05
\end{abstract}


KOMIK (Konferensi Nasional Teknologi Informasi dan Komputer)

Volume 3, Nomor 1, Oktober 2019

DOI: $10.30865 /$ komik.v3i1.1588
ISSN 2597-4645 (media online)

ISSN 2597-4610 (media cetak)

Page: 187-198

\begin{tabular}{|c|c|c|c|c|}
\hline \multirow[t]{2}{*}{ T47 } & $\mathrm{b} 81 \mathrm{e} 85 \mathrm{~d} 427045550$ & $371 \mathrm{f} 12 \mathrm{f} 333 \mathrm{f} 7 \mathrm{e} 5 \mathrm{~b} 9$ & 1e99cae9d4cf0409 & b4838c1c28fee7bc \\
\hline & $5 f 3 c 64 b 7546 e 2 c e c$ & ae70c7d11 ea84a83 & $\mathrm{a} 2 \mathrm{a} 475 \mathrm{deac} 0 \mathrm{e} 8 \mathrm{~b} 42$ & f5794711faa60f63 \\
\hline \multirow[t]{2}{*}{$\mathbf{T} 48$} & e08471946c17b0b6 & b81e85d427045550 & $371 \mathrm{f} 12 \mathrm{f} 333 \mathrm{f} 7 \mathrm{e} 5 \mathrm{~b} 9$ & 1e99cae9d4cf0409 \\
\hline & $\mathrm{c} 45 \mathrm{dd} 4 \mathrm{a} 2 \mathrm{~d} 2 \mathrm{fea} 059$ & $5 f 3 c 64 b 7546 e 2 c e c$ & ae70c7d11ea84a83 & a2a475deac0e8b42 \\
\hline \multirow[t]{2}{*}{ T49 } & bf8d9453b9876b0a & e08471946c17b0b6 & $\mathrm{b} 81 \mathrm{e} 85 \mathrm{~d} 427045550$ & $371 \mathrm{f} 12 \mathrm{f} 333 \mathrm{f} 7 \mathrm{e} 5 \mathrm{~b} 9$ \\
\hline & 59d0238ce137abd7 & $\mathrm{c} 45 \mathrm{dd} 4 \mathrm{a} 2 \mathrm{~d} 2 \mathrm{fea} 059$ & $5 f 3 c 64 b 7546 e 2 c e c$ & ae70c7d11ea84a83 \\
\hline \multirow[t]{2}{*}{ T50 } & 714e2adf4e23ff24 & bf8d9453b9876b0a & e08471946c17b0b6 & $\mathrm{b} 81 \mathrm{e} 85 \mathrm{~d} 427045550$ \\
\hline & $48253 \mathrm{e} 21 \mathrm{~b} 26 \mathrm{~d} 8 \mathrm{cf} 9$ & 59d0238ce137abd7 & $\mathrm{c} 45 \mathrm{dd} 4 \mathrm{a} 2 \mathrm{~d} 2 \mathrm{fea} 059$ & $5 \mathrm{f} 3 \mathrm{c} 64 \mathrm{~b} 7546 \mathrm{e} 2 \mathrm{cec}$ \\
\hline \multirow[t]{2}{*}{ T51 } & $6 \mathrm{c} 27893 \mathrm{a} 31 \mathrm{~b} 0 \mathrm{e} 07 \mathrm{e}$ & 714e2adf4e23ff24 & bf8d9453b9876b0a & e08471946c17b0b6 \\
\hline & ccf99a80f92bf004 & $48253 \mathrm{e} 21 \mathrm{~b} 26 \mathrm{~d} 8 \mathrm{cf} 9$ & 59d0238ce137abd7 & $\mathrm{c} 45 \mathrm{dd} 4 \mathrm{a} 2 \mathrm{~d} 2 \mathrm{fea} 059$ \\
\hline \multirow[t]{2}{*}{ T52 } & ae993474363efe68 & $6 \mathrm{c} 27893 \mathrm{a} 31 \mathrm{~b} 0 \mathrm{e} 07 \mathrm{e}$ & 714e2adf4e23ff24 & bf8d9453b9876b0a \\
\hline & 587f308d58681928 & ccf99a80f92bf004 & $48253 \mathrm{e} 21 \mathrm{~b} 26 \mathrm{~d} 8 \mathrm{cf} 9$ & 59d0238ce137abd7 \\
\hline \multirow[t]{2}{*}{ T53 } & ccf99a80f92bf002 & ae993474363efe68 & $6 c 27893 \mathrm{a} 31 \mathrm{~b} 0 \mathrm{e} 07 \mathrm{e}$ & $714 \mathrm{e} 2 \mathrm{adf} 4 \mathrm{e} 23 \mathrm{ff} 24$ \\
\hline & a7bbd65bf64f58c8 & 587f308d58681928 & ccf99a80f92bf004 & $48253 \mathrm{e} 21 \mathrm{~b} 26 \mathrm{~d} 8 \mathrm{cf} 9$ \\
\hline \multirow[t]{2}{*}{ T54 } & e52a24fae 4 e $8 f c 9 b$ & ccf99a80f92bf002 & ae993474363efe68 & $6 \mathrm{c} 27893 \mathrm{a} 31 \mathrm{~b} 0 \mathrm{e} 07 \mathrm{e}$ \\
\hline & 042c2dc9a5bf558a & a7bbd65bf64f58c8 & $587 f 308 d 58681928$ & ccf99a80f92bf004 \\
\hline \multirow[t]{2}{*}{ T55 } & 7799c75acc748c0f & $\mathrm{e} 52 \mathrm{a} 24 \mathrm{fae} 4 \mathrm{e} 8 \mathrm{fc} 9 \mathrm{~b}$ & ccf99a80f92bf002 & ae993474363efe 68 \\
\hline & 19316bebc88e01f2 & 042c2dc9a5bf558a & a7bbd65bf64f58c8 & 587f308d58681928 \\
\hline \multirow[t]{2}{*}{ T56 } & eb85d19201c89694 & 7799c75acc748c0f & e52a24fae $4 e 8 f c 9 b$ & ccf99a80f92bf002 \\
\hline & 9 ced24983eec8723 & $19316 \mathrm{bebc} 88 \mathrm{e} 01 \mathrm{f} 2$ & 042c2dc9a5bf558a & a7bbd65bf64f58c8 \\
\hline \multirow[t]{2}{*}{ T57 } & 24a1124262a331c7 & eb85d19201c89694 & 7799c75acc748c0f & $\mathrm{e} 52 \mathrm{a} 24 \mathrm{fae} 4 \mathrm{e} 8 \mathrm{fc} 9 \mathrm{~b}$ \\
\hline & 06edacae6e7b54ad & 9 ced 24983 eec 8723 & 19316bebc $88 \mathrm{e} 01 \mathrm{f} 2$ & $042 \mathrm{c} 2 \mathrm{dc} 9 \mathrm{a} 5 \mathrm{bf} 558 \mathrm{a}$ \\
\hline \multirow[t]{2}{*}{ T58 } & 56fb5883f1c87a05 & 24a1124262a331c7 & eb85d19201c89694 & $7799 \mathrm{c} 75 \mathrm{acc} 748 \mathrm{c} 0 \mathrm{f}$ \\
\hline & 617bbf70bb165211 & 06edacae6e7b54ad & 9 ced24983eec8723 & 19316bebc88e01f2 \\
\hline \multirow[t]{2}{*}{ T59 } & f5198a41eb80e022 & $56 \mathrm{fb} 5883 \mathrm{f} 1 \mathrm{c} 87 \mathrm{a} 05$ & $24 \mathrm{a} 1124262 \mathrm{a} 331 \mathrm{c} 7$ & eb85d19201c89694 \\
\hline & 3dc764f89e54043a & 617bbf70bb165211 & 06edacae6e7b54ad & $9 \operatorname{ced} 24983$ eec 8723 \\
\hline \multirow[t]{2}{*}{ T60 } & a57784945550cf92 & f5198a41eb80e022 & 56fb5883f1c87a05 & $24 \mathrm{a} 1124262 \mathrm{a} 331 \mathrm{c} 7$ \\
\hline & eac5516336bc8882 & $3 \mathrm{dc} 764 \mathrm{f} 89 \mathrm{e} 54043 \mathrm{a}$ & $617 \mathrm{bbf} 70 \mathrm{bb} 165211$ & 06edacae6e7b54ad \\
\hline \multirow[t]{2}{*}{ T61 } & $69 \mathrm{c} 8 \mathrm{f} 40 \mathrm{eb} 38 \mathrm{~b} 6022$ & a57784945550cf92 & f5198a41eb80e022 & $56 \mathrm{fb} 5883 \mathrm{f} 1 \mathrm{c} 87 \mathrm{a} 05$ \\
\hline & $177589502 d d 39 a a 2$ & eac5516336bc8882 & 3dc764f89e54043a & 617bbf70bb165211 \\
\hline \multirow[t]{2}{*}{ T62 } & $97901 \mathrm{f} 333 \mathrm{e} 662 \mathrm{fdc}$ & $69 \mathrm{c} 8 \mathrm{f} 40 \mathrm{eb} 38 \mathrm{~b} 6022$ & a57784945550cf92 & f5198a41eb80e022 \\
\hline & 4472b2e331ddfab4 & 177589502dd39aa2 & eac5516336bc8882 & $3 \mathrm{dc} 764 \mathrm{f} 89 \mathrm{e} 54043 \mathrm{a}$ \\
\hline \multirow[t]{2}{*}{ T63 } & $89 \mathrm{dc} 825 \mathrm{e} 7235 \mathrm{c} 74 \mathrm{~b}$ & $97901 \mathrm{f} 333 \mathrm{e} 662 \mathrm{fdc}$ & $69 \mathrm{c} 8 \mathrm{f} 40 \mathrm{eb} 38 \mathrm{~b} 6022$ & a57784945550cf92 \\
\hline & 7a499ae05da50bf2 & 4472b2e331ddfab4 & $177589502 d d 39 a a 2$ & eac5516336bc8882 \\
\hline \multirow[t]{2}{*}{ T64 } & 356d08d982e2ead4 & $89 \mathrm{dc} 825 \mathrm{e} 7235 \mathrm{c} 74 \mathrm{~b}$ & $97901 \mathrm{f} 333 \mathrm{e} 662 \mathrm{fdc}$ & 69c8f40eb38b6022 \\
\hline & 40c28c34b1bbe906 & 7a499ae05da50bf2 & $4472 \mathrm{~b} 2 \mathrm{e} 331 \mathrm{ddfab} 4$ & $177589502 \mathrm{dd} 39 \mathrm{aa} 2$ \\
\hline \multirow[t]{2}{*}{ T65 } & $75476 f 5456 e 82 f 9 c$ & 356d08d982e2ead4 & $89 \mathrm{dc} 825 \mathrm{e} 7235 \mathrm{c} 74 \mathrm{~b}$ & $97901 \mathrm{f} 333 \mathrm{e} 662 \mathrm{fdc}$ \\
\hline & $3024702447 f 76224$ & 40c28c34b1bbe 906 & 7a499ae05da50bf2 & 4472b2e331ddfab4 \\
\hline \multirow[t]{2}{*}{ T66 } & $7416 \mathrm{ca} 18 \mathrm{~d} 9 \mathrm{e} 265 \mathrm{e} 0$ & $75476 f 5456 e 82 f 9 c$ & 356d08d982e2ead4 & $89 \mathrm{dc} 825 \mathrm{e} 7235 \mathrm{c} 74 \mathrm{~b}$ \\
\hline & $11200 \mathrm{c} 2 \mathrm{~d} 47 \mathrm{c} 082 \mathrm{f} 8$ & $3024702447 f 76224$ & 40c28c34b1bbe906 & 7a499ae05da50bf2 \\
\hline \multirow[t]{2}{*}{ T67 } & e7748fbf744a5240 & 7416ca18d9e265e0 & $75476 \mathrm{f} 5456 \mathrm{e} 82 \mathrm{f} 9 \mathrm{c}$ & $356 \mathrm{~d} 08 \mathrm{~d} 982 \mathrm{e} 2 \mathrm{ead} 4$ \\
\hline & 0d7ab03208f1d7a5 & $11200 \mathrm{c} 2 \mathrm{~d} 47 \mathrm{c} 082 \mathrm{f} 8$ & $3024702447 f 76224$ & $40 \mathrm{c} 28 \mathrm{c} 34 \mathrm{~b} 1 \mathrm{bbe} 906$ \\
\hline T68 & b4cb0df332d108ab & e7748fbf744a5240 & $7416 \mathrm{ca} 18 \mathrm{~d} 9 \mathrm{e} 265 \mathrm{e} 0$ & $75476 f 5456 \mathrm{e} 82 \mathrm{f} 9 \mathrm{c}$ \\
\hline & $8 \mathrm{fe} 3 \mathrm{~d} 28097 \mathrm{f} 18618$ & 0d7ab03208f1d7a5 & $11200 \mathrm{c} 2 \mathrm{~d} 47 \mathrm{c} 082 \mathrm{f} 8$ & $3024702447 f 76224$ \\
\hline T69 & 6db5469fa19c0e27 & b4cb0df332d108ab & e7748fbf744a5240 & $7416 \mathrm{ca} 18 \mathrm{~d} 9 \mathrm{e} 265 \mathrm{e} 0$ \\
\hline & 16beec0fec168e79 & $8 \mathrm{fe} 3 \mathrm{~d} 28097 \mathrm{f} 18618$ & 0d7ab03208f1d7a5 & $11200 \mathrm{c} 2 \mathrm{~d} 47 \mathrm{c} 082 \mathrm{f} 8$ \\
\hline T70 & $0928 \mathrm{~b} 75 \mathrm{c} 925 \mathrm{f} 91 \mathrm{e} 2$ & $6 \mathrm{db} 5469 \mathrm{fa} 19 \mathrm{c} 0 \mathrm{e} 27$ & b4cb0df332d108ab & e7748fbf744a5240 \\
\hline & 79f4be3c5a372911 & 16beec0fec168e79 & $8 \mathrm{fe} 3 \mathrm{~d} 28097 \mathrm{f} 18618$ & 0d7ab03208f1d7a5 \\
\hline T71 & $44 \mathrm{ea} 14 \mathrm{~d} 8 \mathrm{e} 450 \mathrm{c} 844$ & 0928b75c925f91e2 & 6db5469fa19c0e27 & b4cb0df332d108ab \\
\hline & 5319374fb88dd485 & 79f4be3c5a372911 & 16beec0fec168e 79 & $8 \mathrm{fe} 3 \mathrm{~d} 28097 \mathrm{f} 18618$ \\
\hline T72 & $3 a 38 f a 3775 d 7007 c$ & 44ea14d8e450c844 & 0928b75c925f91e2 & 6db5469fa19c0e27 \\
\hline & e26f3a21e9a27691 & $5319374 f b 88 d d 485$ & 79f4be3c5a372911 & 16beec0fec168e79 \\
\hline
\end{tabular}

Page | 196

http://ejurnal.stmik-budidarma.ac.id/index.php/komik 


\begin{tabular}{lllll} 
T73 & 5ec3802b9ecfef33 & 3a38fa3775d7007c & 44ea14d8e450c844 & 0928b75c925f91e2 \\
& 88146da76ff6f23a & e26f3a21e9a27691 & 5319374fb88dd485 & 79f4be3c5a372911 \\
T74 & 7001201948fb3d71 & 5ec3802b9ecfef33 & 3a38fa3775d7007c & 44ea14d8e450c844 \\
& e1053fc85f9e56be & 88146da76ff6f23a & e26f3a21e9a27691 & 5319374fb88dd485 \\
\multirow{2}{*}{ T75 } & 5f2eead69efb4233 & 7001201948fb3d71 & 5ec3802b9ecfef33 & 3a38fa3775d7007c \\
& 8901cffe7a74db98 & e1053fc85f9e56be & 88146da76ff6f23a & e26f3a21e9a27691 \\
T76 & 5cdf6c58fc052572 & 5f2eead69efb4233 & 7001201948fb3d71 & 5ec3802b9ecfef33 \\
& 4779767cc2ec5321 & 8901cffe7a74db98 & e1053fc85f9e56be & 88146da76ff6f23a \\
T77 & 4abe0af6a67db2fe & 5cdf6c58fc052572 & 5f2eead69efb4233 & 7001201948fb3d71 \\
& 500f7b61186f6c2e & 4779767cc2ec5321 & 8901cffe7a74db98 & e1053fc85f9e56be \\
T78 & abab4b0ca75a17c7 & 4abe0af6a67db2fe & 5cdf6c58fc052572 & 5f2eead69efb4233 \\
& d42c3a57cfa78513 & 500f7b61186f6c2e & 4779767cc2ec5321 & 8901cffe7a74db98 \\
T79 & 14e986342ddced0f & abab4b0ca75a17c7 & 4abe0af6a67db2fe & 5cdf6c58fc052572 \\
& 8347f5736531b3ec & d42c3a57cfa78513 & 500f7b61186f6c2e & 4abe0af6a67db2fe
\end{tabular}

Setelah menginisialisasi 8 variabel tersebut, selanjutnya hasil akhir dari perhitungan dijumlahkan dengan nilai value.

$\mathrm{HO}^{(1)}=$ cbbb9d5dc1059ed $8+14 \mathrm{e} 986342$ ddced0f $=\mathrm{e} 0 \mathrm{a} 52391$ eee $28 \mathrm{be} 7$

$\mathrm{H} 1^{(1)}=629 \mathrm{a} 292 \mathrm{a} 367 \mathrm{~cd} 507+\mathrm{abab} 4 \mathrm{~b} 0 \mathrm{ca} 75 \mathrm{a} 17 \mathrm{c} 7=\mathrm{e} 457436 \mathrm{ddd} 6 \mathrm{ecce}$

$\mathrm{H} 2^{(1)}=9159015 \mathrm{a} 3070 \mathrm{dd} 17+4 \mathrm{abe} 0 \mathrm{af} 6 \mathrm{a} 67 \mathrm{db} 2 \mathrm{fe}=\mathrm{dc} 170 \mathrm{c} 50 \mathrm{~d} 6 \mathrm{ee} 9015$

$\mathrm{H}^{(1)}=152 \mathrm{fecd} 8 \mathrm{f} 70 \mathrm{e} 5939+5 \mathrm{cdf} 6 \mathrm{c} 58 \mathrm{fc} 052572=720 \mathrm{f} 5931 \mathrm{f} 3137 \mathrm{eab}$

$\mathrm{H} 4^{(1)}=67332667 \mathrm{ffc} 00 \mathrm{~b} 31+8347 \mathrm{f} 5736531 \mathrm{~b} 3 \mathrm{ec}=\mathrm{ea} 7 \mathrm{~b} 1 \mathrm{bdb} 64 \mathrm{f} 1 \mathrm{bf} 1 \mathrm{~d}$

$\mathrm{H} 5^{(1)}=8 \mathrm{eb} 44 \mathrm{a} 8768581511+\mathrm{d} 42 \mathrm{c} 3 \mathrm{a} 57 \mathrm{cfa} 78513=62 \mathrm{e} 084 \mathrm{df} 37 \mathrm{ff} 9 \mathrm{a} 24$

$\mathrm{H}^{(1)}=\mathrm{db} 0 \mathrm{c} 2 \mathrm{e} 0 \mathrm{~d} 64 \mathrm{f} 98 \mathrm{fa} 7+500 \mathrm{f} 7 \mathrm{~b} 61186 \mathrm{f} 6 \mathrm{c} 2 \mathrm{e}=2 \mathrm{~b} 1 \mathrm{ba} 96 \mathrm{e} 7 \mathrm{~d} 68 \mathrm{fbd} 5$

$\mathrm{H} 7^{(1)}=47 \mathrm{~b} 5481 \mathrm{dbefa} 4 \mathrm{fa} 4+4 \mathrm{abe} 0 \mathrm{af} 6 \mathrm{a} 67 \mathrm{db} 2 \mathrm{fe}=92735314657802 \mathrm{a} 2$

Tabel 8. Hasil Nilai SHA-384

e0a52391eee28be 7

e457436ddd6ecce

dc170c50d6ee9015

720f5931f3137eab

ea7b1bdb64f1bf1d

$62 \mathrm{e} 084 \mathrm{df} 37 \mathrm{ff} 9 \mathrm{a} 24$

$2 \mathrm{~b} 1 \mathrm{ba} 96 \mathrm{e} 7 \mathrm{~d} 68 \mathrm{fbd} 5$

$92735314657802 \mathrm{a} 2$

Berdasarkan dari perhitungan sampel di atas diperoleh nilai SHA-384 berbentuk bilangan hexadesimal 8 karakter 128 byte, yaitu :

= e0a52391eee28be7e457436ddd6eccedc170c50d6ee9015720f5931f3137eabea7b1bdb64f1bf1d62e084df37f

f9a242b1ba96e7d68fbd592735314657802a2".

Jadi nilai hash value yang terakhir adalah nilai yang didapat merupakan sidik jari dari sampel file ijazah tersebut. Jika terjadi perubahan sedikit saja maka nilai ini akan berubah sehingga jika nilainya berubah maka file ijazah tersebut telah di manipulasi. Berikut nilai hash keseluruhan citra digital yang asli:

$=4 \mathrm{e} 557758 \mathrm{c} 950346501 \mathrm{~d} 7451 \mathrm{becb} 46292 \mathrm{e} 238 \mathrm{de} 2 \mathrm{f} 32 \mathrm{~b} 0 \mathrm{e} 8 \mathrm{f} 22099 \mathrm{a} 27 \mathrm{e} 2 \mathrm{~b} 4 \mathrm{ba} 25 \mathrm{~b} 2917 \mathrm{f} 985 \mathrm{e} 7 \mathrm{~b} 5 \mathrm{f} 731 \mathrm{fabe} 222 \mathrm{ff} 0$

4cb6a1".

Tabel 9. hasil pengujian dengan beberapa parameter

\begin{tabular}{|c|c|c|c|c|c|}
\hline Parameter & Citra Asli & Citra Modifikasi & Hash citra asli & $\begin{array}{ll}\text { Hash } & \text { citra } \\
\text { modifikasi }\end{array}$ & Hasil \\
\hline $\begin{array}{l}\text { Mengubah } \\
\text { ukuran } \\
\text { citra digital }\end{array}$ & 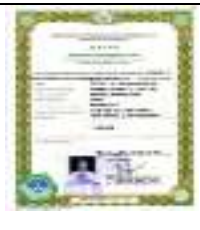 & 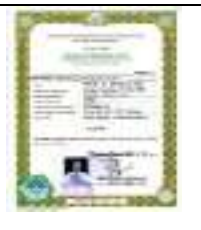 & $\begin{array}{l}\text { 4e557758c950346 } \\
501 \mathrm{~d} 7451 \mathrm{becb} 462 \\
92 \mathrm{e} 238 \mathrm{de} 2 \mathrm{f} 32 \mathrm{~b} 0 \mathrm{e} \\
8 \mathrm{f} 22099 \mathrm{a} 27 \mathrm{e} 2 \mathrm{~b} 4 \mathrm{~b} \\
\mathrm{a} 25 \mathrm{~b} 2917 \mathrm{f} 985 \mathrm{e} 7 \mathrm{~b} \\
5 \mathrm{f} 731 \mathrm{fabe} 222 \mathrm{ff} 04 \\
\text { cb6a1 }\end{array}$ & $\begin{array}{l}\text { 64dd6b1e9df56f119 } \\
\text { 52c42b16ef19fa567d } \\
\text { c2631436295d8bc82 } \\
\text { bd8c7b2242810b1f8 } \\
\text { 02f4029473c4368f0 } \\
\text { 85d9bf5d61 }\end{array}$ & Terdeteksi \\
\hline
\end{tabular}




\begin{tabular}{|c|c|c|c|c|c|}
\hline $\begin{array}{l}\text { Penambahan } \\
\text { titik pada citra } \\
\text { digital }\end{array}$ & 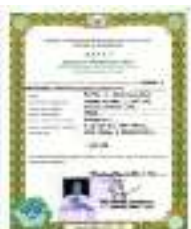 & 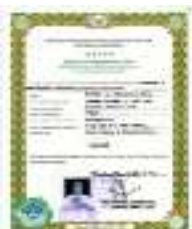 & $\begin{array}{l}\text { 4e557758c950346 } \\
501 \mathrm{~d} 7451 \mathrm{becb} 462 \\
92 \mathrm{e} 238 \mathrm{de} 2 \mathrm{f} 32 \mathrm{~b} 0 \mathrm{e} \\
8 \mathrm{f} 22099 \mathrm{a} 27 \mathrm{e} 2 \mathrm{~b} 4 \mathrm{~b} \\
\mathrm{a} 25 \mathrm{~b} 2917 \mathrm{f} 985 \mathrm{e} 7 \mathrm{~b} \\
\text { 5f731fabe222ff04 } \\
\text { cb6a1 }\end{array}$ & $\begin{array}{l}7900 \mathrm{~b} 02 \mathrm{c} 82 \mathrm{c} 9 \mathrm{a} 5257 \\
\text { 2e88ef56f5994bda3a } \\
\text { cdf2a1a98ce359f949 } \\
766 f 537833 \mathrm{dab} 3124 \\
\text { b111d0fb455ec7838 } \\
46090083 \mathrm{a}\end{array}$ & Terdeteksi \\
\hline $\begin{array}{l}\text { Mengubah } \\
\text { kontras }\end{array}$ & 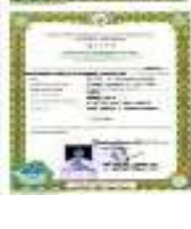 & 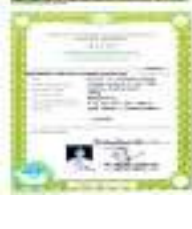 & $\begin{array}{l}\text { 4e557758c950346 } \\
501 \mathrm{~d} 7451 \mathrm{becb} 462 \\
92 \mathrm{e} 238 \mathrm{de} 2 \mathrm{f} 32 \mathrm{~b} 0 \mathrm{e} \\
\text { 8f22099a27e2b4b } \\
\text { a25b2917f985e7b } \\
\text { 5f731fabe222ff04 } \\
\text { cb6a1 }\end{array}$ & $\begin{array}{l}01 d 17 b 8 c 3 e 3822888 \\
\text { f922585bc0577e8db } \\
5 f 257 a a b 16129 d f 780 \\
\text { ed69abf9ff } 1 d 8 a 5750 \\
\text { ea6d7f848e738f113e } \\
4101284 d\end{array}$ & Terdeteksi \\
\hline
\end{tabular}

Berdasarkan dari tabel diatas, hasil pengujian dari algoritma SHA-384 dalam mendeteksi orisinal hasil scan ijazah menunjukkan bahwa 100\% berhasil. Pengujian tersebut menujukkan bahwa perubahan sekecil apapun yang dilakukan akan terdeteksi keasliaan atau modifikasi dari citra digital tersebut dan perubahannya sangat besar perbedaannya.

\section{KESIMPULAN}

Berdasarkan analisa yang telah dilakukan selama proses pengujian. Hasil yang diperoleh dari penelitian yang dilakukan untuk orisinalitas citra digital hasil scan ijazah dengan menggunakan metode SHA-384, maka dapat diambil kesimpulan sebagai berikut:

1. Proses autentikasi citra ijazah dengan cara mendapatkan digital signature file citra ijazah berbentuk hash.

2. Penerapan metode SHA-384 digunakan untuk encoding nilai piksel citra input scan ijazah dan menjadikan hasil hash sebagai nilai baru pada piksel citra ijazah.

3. Algoritma SHA-384 berhasil mendeteksi perubahan yang terjadi pada citra dengan tingkat keberhasilan $100 \%$.

\section{REFERENCES}

[1] william stallings, "cryptography and network security principles and practices 4th edition," 2005.

[2] munir, penggunaan tanda tangan digital untuk menjaga integritas berkas perangkat lunak. yogyakarta, 2005.

[3] Oorcshot. P, and Vansyone. S Menrzes A, Handbook of Applied Cryptography. taylor \& francis, 2010.

[4] M Lavanya, "RFID Systems Equipped With OTP Security Design Using Sha-384 Algorithm," no. 5, pp. 147-150, 2016.

[5] Rifki Sadikin, Kriptografi untuk Keamanan Jaringan dan Implementasiny dalam Bahasa Java. Yogyakarta: Andi, 2012. 